\title{
ESCOLA ESTATAL, ESCOLA PÚBLICA E CONHECIMENTO: AVALIANDO CAMINHOS CONTRADITÓRIOS NA FORMAÇÃO DE PROFESSORES E DE SEUS ALUNOS
}

\author{
Luzia Marta Bellini \\ Adriano Rodrigues Ruiz \\ Professora do Departamento de Fundamentos da Educação \\ Professor do Departamento de Teoria e Prática da Educação \\ da Universidade Estadual de Maringá
}

\begin{abstract}
Resumo
Neste texto avaliamos o quadro síntese de história da educação e teorias da aprendizagem discutido no curso de formação de professores ministrado em 1999 pela Secretaria Municipal de Educação de Maringá. Para analisar este quadro e a formação proposta no curso, tomamos como referência cadernos de lições de um aluno da Rede Municipal do ano anterior, 1998. Tal curso indica a incapacidade de avançarmos na escola como local, de fato, público, onde os conhecimentos deveriam ser a alavanca para uma formação mais integral e inteligente de professores e alunos. O que notamos no curso é uma formação deformada, uma visão distorcida da história e da aprendizagem das crianças.
\end{abstract}




\section{Introdução}

A educação escolarizada tem se constituído, inegavelmente, em lugar privilegiado para a semeadura de valores, práticas e rituais que estimulam a indiferença e o conformismo. É, também, lugar de desapreço ao conhecimento, à felicidade e à vida inteligente. Entendemos ser isso que Reimer (1979: 67) denuncia afirmando: "As escolas aprenderam há muito tempo que a melhor maneira de evitar que as crianças pensem é mantê-las ocupadas".

Preocupados com essa padronização do ser, sentir e estar no mundo, neste artigo, focalizamos dois instantâneos que mostram relações vividas no espaço escolar na busca de conhecimentos: uma delas envolve administração-professor e a outra relação, a do professor e seu aluno.

Ao abordar a relação administração-professor, tomamos como referência os "conhecimentos" oferecidos aos professores da Rede Municipal de Educação de Maringá durante um curso de "capacitação docente", em julho de 1999. Quanto à relação professor-aluno, vamos identificá-la observando os cadernos (de 1997 e 1998) de uma criança que estuda em uma escola dessa mesma Rede.

Esses dois instantâneos, vividos em momentos distintos, são, para nós, frutos da submissão a um mesmo espírito: o espírito da imposição de modelos e do desapreço aos conhecimentos. Mais ainda, o imperar desse espírito, sabemos, impõe à criança a renúncia à curiosidade, à autonomia moral e intelectual e ao professor impõe o papel de porta-voz da Secretaria. Os instantâneos, assim percebidos, são compatíveis com a escola situada como instância reguladora.

Por isso, salvo poucas exceções, a escola tem se ocupado mais na modelagem da criança e do jovem pelas maneiras de viver a sociedade dos adultos: desde muito cedo constrói um "indivíduo tipificado, em modelo personológico estereotipado" (Guattari, 1986: 54). Tal empreitada 
educacional traduz a escola como espaço micropolítico onde o consciente e o inconsciente da criança ficam inteiramente contaminados pelos conflitos dos adultos: da competição, das lutas para "saber" mais, do trabalho... enfim, por estar em posições do sistema capitalístico.

As aquisições da linguagem escritas e do chamado raciocínio lógicas rápido sugerem uma série de operações e técnicas de aprendizagem que estão intimamente vinculadas à política de adaptação das crianças - "aos valores, significações e comportamentos dominantes" (idem: 53).

O essencial para a padronização, diz Guattari, "já não é a aprendizagem da língua materna", ou diríamos, do conhecimento de nossa cultura, dos clássicos etc., mas impor linguagens como técnicas para a fala, para o "raciocínio". É nesse sentido que a escola vive o "efeito da política semiótica dos adultos sobre as crianças" (p. 53) que implica, em outras palavras, dominar as crianças desde cedo para aceitarem, mais tarde, a sociedade que lhes imporá o trabalho fragmentado, repetitivo e mesmo a exclusão do trabalho.

Não mandamos, diz Guattari, para as manufaturas crianças de 6 a 8 anos, porém, as enviamos para uma aprendizagem nas escolas que operam com técnicas de ensino, com técnicas audiovisuais que fazem o trabalho com mais suavidade do que as palmatórias e os castigos corporais e "em muito maior profundidade".

A supervisão, a orientação e a direção da escola encarregam-se da valorização dessa micropolítica de adaptação: elas tomam os diferentes códigos de vivência das crianças e homogeneízam a um único código semiótico: os códigos de poder e de prestígio social. Assim, impõe-se à criança repetir à exaustão, copiar centenas de linhas de números, decorar palavras e letras. É essa a dura lição que a burocracia nos ensina a manter nos espaços de aprendizagem - na verdade - territórios do ensino da micropolítica do abandono ao conhecimento e do desamor à língua materna e ao conhecimento de uma forma geral.

Percorrendo, assim, os caminhos da educação formal, vemos que escola e conhecimento soam como dimensões antinômicas. O que fazem os "administradores escolares" das Secretarias do Estado e/ou município até os da vida interna das escolas? Como a burocracia escolar alimenta a dicotomia entre o fazer e o pensar dos professores?

A burocracia violenta o professor em sua dimensão intelectual, transformando-o em porta-voz do Estado ou do município. Como porta- 
voz - apenas alguém que repete as mensagens de seus superiores - são negadas muitas coisas, sobretudo, o pensamento divergente. Uma educação que desconhece a pluralidade, seja epistêmica, social, ideológica, étnica, de estilos cognitivos... perde seu caráter público por se tornar um instrumento de exclusão daqueles - professores e alunos - menos dóceis ao ato de reverenciar crenças e caprichos dos "mandarins". Esse é o percurso que faz emergir a escola estatal. Nossa idéia é a de que a escola que chamamos de pública, neste contexto de modelagem de professores a alunos, não passa de escola estatal. Não pagamos pela educação de nossas crianças e jovens, mas também pagamos um alto preço por estarmos sendo tutelados por chefes, subchefes e mandarins de várias ordens. O caráter público, de fato, ainda está por vir.

A partir do quadro delineado, mostraremos que com a renúncia ao fazer intelectual no espaço escolar, professores, crianças e pais entram em um mundo regido pelo signo do autoritarismo.

\section{O desapreço pelo estudo e o amor à verbosidade: o conhecimento substituído por rótulos}

É inegável que a escola tem poucas preocupações com o conhecimento. Em seu território as preocupações consistentes falam de outras coisas, entre elas: disciplina, obediência, modelos, planejamentos e controles. É, também, o lugar de ausências: da reflexão política, da compreensão do desenvolvimento infantil, do conhecimento do conhecimento que se diz ensinar... O amálgama usado para cobrir as ausências é o discurso. Discurso bem neste sentido denunciado por Paulo Freire (1992: 101):

Quase sempre, ao se criticar esse gosto pela palavra oca, da verbosidade, em educação, se diz dela que seu pecado é ser "teórica". Identifica-se assim, absurdamente, teoria como verbalismo. De teoria, na verdade precisamos nós. De teoria que implica uma inserção na realidade, num contato analítico com o existente, para comprová-lo, para vivê-lo e vivê-lo plenamente, praticamente. (...) Nossa educação não é teórica porque lhe falta esse gosto da comprovação, da invenção, da pesquisa. Ela é verbosa. 
Com preocupações dessa natureza, nossos olhares voltaram-se para esta pergunta: como transcorre um dia de estudos dos professores de uma rede educação pública? Na busca de indicações para compor respostas, em julho de 1999, conversamos sobre isso com professores da Rede Municipal de Educação de Maringá, logo após uma sessão de estudos desenvolvida sob a tutela da Secretaria.

Pelos relatos dos professores, percebemos que a eles foi imposto o exercício da verbosidade, os materiais usados foram xerox de fragmentos de livros e uma coletânea de rótulos sob a forma de um quadro-síntese. 0 que poderia ser um momento para a reflexão sobre conhecimentos, para a discussão de sistemas de idéias, transformou-se na imposição de um palavreado que anuncia caricaturas grotescas de epistemologias e da história da educação.

Com palavreado "oco", são enunciados fragmentos de "crenças" como estes: "a escola é a única condição de modificar a miséria"; "compreensão do papel da escola na produção da marginalidade"; "aluno desajustado não se integra". Um festival de impropriedades que torna possível, até mesmo, a existência de um humanismo moderno sustentado no comportamentalismo.

O apego dos burocratas à palavra vazia impede que os professores em seus momentos de estudos discutam, por exemplo, relatos de experiências sobre escolas democráticas, pesquisas sobre aprendizagem matemática, estudos que abordam a formação de conceitos científicos, trabalhos acerca da construção da moralidade infantil ou investigações que falam da poesia na escola.

Um ambiente marcado pela verbosidade é vazio intelectualmente e por isso comporta palavras malditas, entre elas: conhecimento, alteridade, lógica, pensamento, autonomia... Malditos são também os estudiosos que as pronunciam e as defendem. Por isso a história da educação aparece em drágeas que desprezam, de fato, a história; a epistemologia surge como coletânea de jargões. Eis o quadro-síntese que foi o centro da sessão de estudos: 


\begin{tabular}{|c|c|c|c|c|c|}
\hline CONCEPÇÕES & TEORIAS & $\begin{array}{c}\text { VISÃO DE } \\
\text { MARGINALIDADE }\end{array}$ & VISÃO DE HOMEM & CONTEXTO & POSIÇÕES \\
\hline $\begin{array}{l}\text { Humanista } \\
\text { tradicional }\end{array}$ & $\begin{array}{c}\text { Fase jesuítica } \\
\text { Influência européia } \\
\text { Herbart }\end{array}$ & Desvio a ser corrigido & $\begin{array}{c}\text { Essencialista. Ser completo. } \\
\text { Teoria do homúnculo }\end{array}$ & Oligarquias rurais & Redenção \\
\hline Humanista moderna & $\begin{array}{c}\text { Escola nova: } \\
\text { psicologismo. Teorias } \\
\text { comportamentais }\end{array}$ & $\begin{array}{l}\text { Aluno desajustado: não } \\
\text { se integra. Escola - única } \\
\text { condição modificar } \\
\text { miséria. }\end{array}$ & $\begin{array}{l}\text { 1) Tábula rasa. } \\
\text { 2) Criança: não mais o } \\
\text { adulto em miniatura. } \\
\text { 3) Inatismo - estruturas } \\
\text { pré-formadas. }\end{array}$ & $\begin{array}{c}\text { Industrialização e } \\
\text { Urbanização }\end{array}$ & Redenção \\
\hline Analítica & $\begin{array}{l}\text { Produções dos } \\
\text { educadores: } \\
\text { preocupação com a } \\
\text { análise dos termos } \\
\text { educacionais. }\end{array}$ & $\begin{array}{c}\text { Grupos ou classes sociais } \\
\text { sem força material. }\end{array}$ & Homem para o mercado. & $\begin{array}{l}\text { Entrado do capital } \\
\text { estrangeiro no país. } \\
\text { Golpe militar }\end{array}$ & Redenção \\
\hline $\begin{array}{l}\text { Crítico- } \\
\text { reproducionistas. }\end{array}$ & $\begin{array}{c}\text { Ensino- violência } \\
\text { simbólica. Escola - } \\
\text { aparelho ideológico do } \\
\text { Estado. Escola dualista. }\end{array}$ & $\begin{array}{c}\text { Sem solução. A escola } \\
\text { reproduz a sociedade de } \\
\text { classes }\end{array}$ & Historicamente situado. & Sociedade capitalista. & Reprodução \\
\hline Crítica e Resistência & $\begin{array}{l}\text { Escola de Frankfurt. } \\
\text { Teorias sociológicas. } \\
\text { Currículo oculto. } \\
\text { Currículos Básicos. }\end{array}$ & $\begin{array}{l}\text { Resistência à opressão e } \\
\text { discriminação - } \\
\text { Possibilidades de } \\
\text { superação. }\end{array}$ & Sujeito histórico. & Sociedade capitalista. & Resistência \\
\hline Histórico-crítica & $\begin{array}{l}\text { Materialismo histórico. } \\
\text { Dialética materialista. } \\
\text { Visão sócio-histórica. }\end{array}$ & $\begin{array}{l}\text { Compreensão do papel } \\
\text { da escola na produção } \\
\text { da marginalidade. }\end{array}$ & $\begin{array}{l}\text { Sujeito histórico. Educação } \\
\text { contribui para a } \\
\text { transformação coletiva da } \\
\text { sociedade. }\end{array}$ & $\begin{array}{l}\text { Abertura política. } \\
\text { Transnacionalização } \\
\text { da economia }\end{array}$ & Transformação \\
\hline
\end{tabular}


Jogar com jargões, ao invés de idéias, leva os professores a caminharem por uma rota que dispensa a teoria, a postura reflexiva, o sobressalto ao perceber contradições, o desconforto do não-conhecer... é o percurso do porta-voz. O segredo da preservação desse modo de ser reside em atribuir a algumas expressões o poder mágico de dizerem tudo, de explicarem tudo: esse é o segredo da "economia de pensamento". Por exemplo, as expressões "homem para o mercado" e "sujeito histórico" são pronunciadas como se explicitassem as múltiplas facetas de nossa historicidade, como se dissessem palavras definitivas sobre a cognição humana, como se definissem paradigmas para as ciências.

Essas práticas escorregadias, que tão velozes se distanciam das teorias, lembram-nos Morin (1991) dizendo que "a patologia moderna do espírito está na hiper-simplificação que o torna cego perante a complexidade do real". A cultura escolar por não ser amante da teoria é reducionista e fecha-se em torno de velhas práticas e velhas verdades. Por isso, desconhece as pesquisas atuais sobre conhecimento, subtraindo dos professores e das crianças múltiplas possibilidades. A implicação direta disso é penalizar de forma mais cortante as crianças das famílias mais empobrecidas: preparando-as para serem "demitidas da vida". Viviane Forrester (1997: 80), em seu livro O horror econômico, fala disso com muito vigor:

(...) o ensino poderia pelo menos adotar como meta oferecer a essas gerações marginais uma cultura que desse sentido à sua presença no mundo, à simples presença humana, permitindo-lhes adquirir uma visão geral das possibilidades reservadas aos seres humanos, uma abertura sobre os campos de seus conhecimentos. E, a partir daí, razões de viver, caminhos a abrir, um sentido para seu dinamismo imanente.

Esse percurso de privação, abençoado por "mandarins" que representam o poder público, impõe aos professores a odiosa prática que Paulo Freire denominou "cultura do silêncio". Isso lembra-nos Piaget (1998: 154), o pensador maior da inteligência humana, falando que:

A educação da liberdade supõe inicialmente uma educação da inteligência e mais especialmente da razão. (...) É preciso ensinar os alunos a pensar, e é impossivel aprender a pensar sob um regime autoritário. Pensar é procurar por si mesmo, é criticar 
livremente e é demonstrar de forma autônoma. O pensamento supõe, portanto, o jogo livre das funções intelectuais, e não o trabalho sob coerção e a repetição verbal.

Por que impor aos professores a repetição de jargões? Entendemos que esse procedimento visa proteger a burocracia da complexidade própria de qualquer espécie de pluralismo. O autoritarismo é vital para a perenidade da cultura empobrecida em que as pessoas lêem fragmentos de capítulos que desconhecem capa e outros capítulos. Aí está presente uma sabedoria que diz: é mais fácil consumir letras do que debater idéias. Uma pergunta que surge a partir dessa é percepção é: como ficam as crianças?

\section{Lições de desapreço ao conhecimento}

"Em lugar de comunicar-se, o educador faz 'comunicados' e depósitos que os educandos, meras incidências, recebem pacientemente, memorizam e repetem." Paulo Freire

A ação educativa quando distante do prazer de conhecer, de pensar e de jogar com idéias aproxima-se de práticas que impõem às crianças o trânsito penoso por labirintos obscuros nos quais as menos plásticas para a modelagem vão enfrentando as rudezas do desamor, das cobranças para se deixar moldar, do contato precoce com a violência.

O professor quando distante da reflexão epistemológica, do contato com o pensamento científico de sua época, da compreensão da lógica infantil, do apreço ao conhecimento fatalmente prende-se a dogmas. A partir daí nasce uma concepção de educação que deposita muita confiança na comunhão de dois sacrifícios: o de ensinar e o de aprender. A comunhão desses sacrifícios tem por morada um espaço nebuloso em que as coisas perdem sua significação própria, por exemplo, conhecer as coisas do mundo (ler, estudar, fazer etc) e ser castigado soam como designando a mesma idéia. Na maioria das vezes, os conhecimentos estão associados à repetição de chamados conteúdos, na decoréba, na lista imensa de exercícios sem o menor significado cognitivo. Isso não é uma forma de conceber o conhecimento como castigo?

Vejamos como nesse lugar de estranhas metamorfoses, a matemática que Jacquard (1998: 104) afirma ser "sobretudo uma ginástica do espírito" 
é transformada em fonte inexaurível de castigos. Nos cadernos $^{1}$ de nossas crianças encontramos "lições" como estas:

(Faça números de 10 em 10 de 500 a 1500)

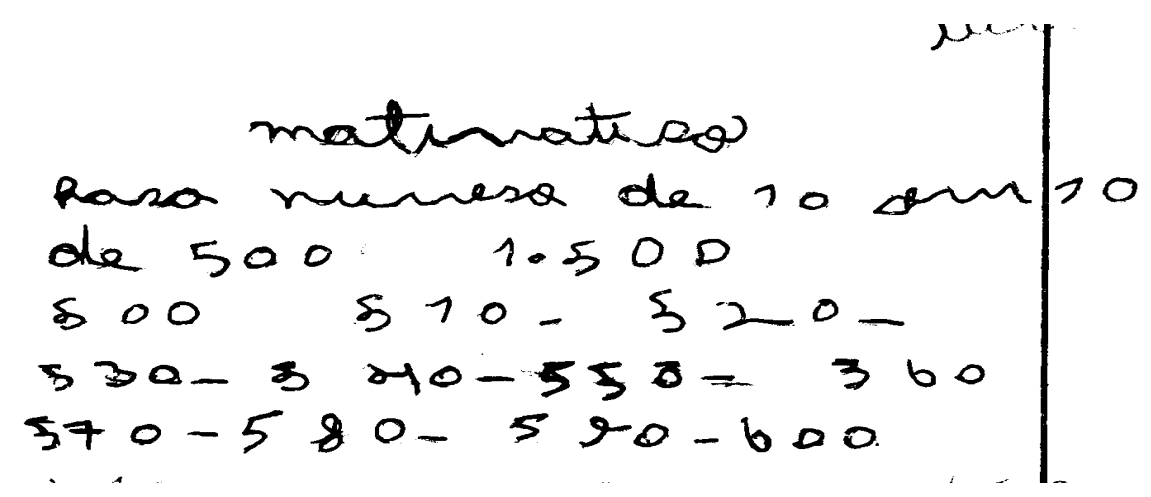

Fazer a tabuada do 2 ao nove.

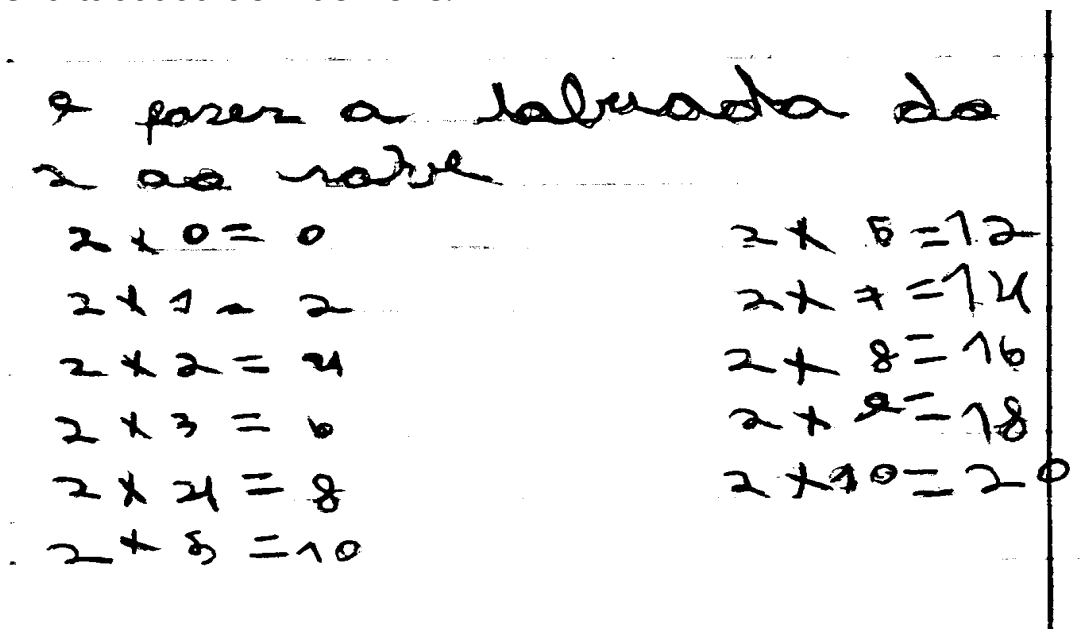

Números de 0 a 150

1 A criança, dona dos cadernos que citamos, estuda em uma escola da Rede Municipal de Educação de Maringá. 
(2) nv ne ROSDC OAT5O

$$
\begin{aligned}
& 0-1-2-3-4-\sqrt{3}-b{ }^{-7-} \\
& 8-9-10-11-1213-19
\end{aligned}
$$

(Faça números de 0 a 200)

$$
\begin{aligned}
& \text { FA SANUNR RCAS DS } \\
& 0 A 200 \\
& -7-2-3-9-5-b-7-8- \\
& 9-12-7-72-73-78 \\
& 74-75-7 b-77-78-14 \\
& 20-27-22-23-24-
\end{aligned}
$$

Escreva números de 0 a 1000

$$
\begin{gathered}
1-2-3-4-5-8-7-8-9- \\
11-12-13-14-15-16- \\
1
\end{gathered}
$$

Depois de 206 penosas linhas, a criança continua

$$
\begin{aligned}
& 915-91 b-9117-998 \\
& 918-420-921-922-92
\end{aligned}
$$

$\operatorname{s\Omega } Q_{2}$

128

Estudos em Avaliação Educacional, n² 23, jan-jun/2001 
$\mathrm{E}$, num dos raros momentos de "pesquisa", algo muito pobre desponta no meio do caderno com a letra da professora:

\section{PESQUISA}

\section{VOCE NASCEU DE DIA OU DE} NOITE ?DE I

Em outro lugar do caderno, as letras ao invés de serem usadas para compor belas histórias, para falar da beleza das flores, para com a magia da sensibilidade compor sublimes poesias, para contar novidades aos amigos, para dizer coisas engraçadas... são reduzidas ao servil papel de entediante "lições":

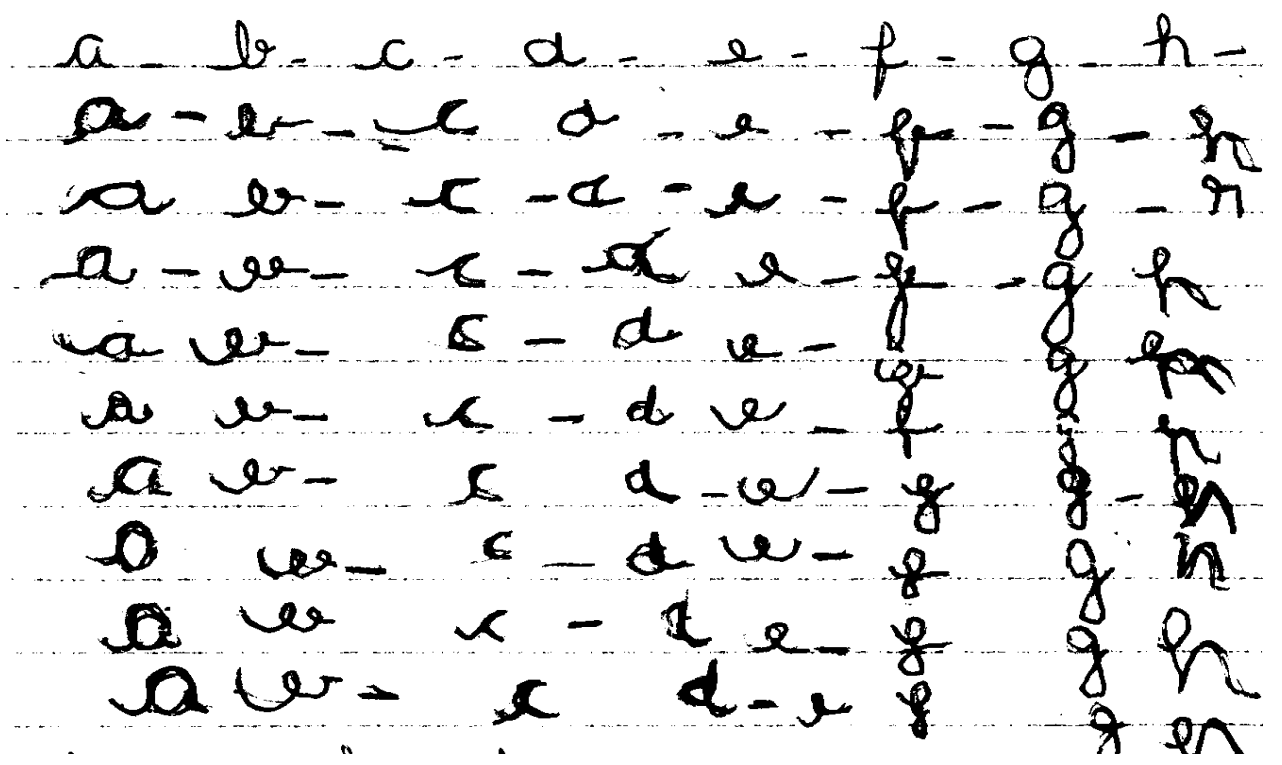

Do exercício de recitar jargões à prática dita "transformadora" da escola, as vítimas diretas são as crianças: umas sentam e obedecem. Algumas - que podem ser as mais brilhantes - querem dizer "professora, nós não somos imbecis!" e, para isso, usam linguagens nem sempre muito convencionais. Esse grito, muitas vezes silencioso, provoca a ira da 
professora que busca, então, novos aliados para ampliar as imposições sobre a criança.

\section{A perversão acadêmica violentando a relação criança-família}

A professora, treinada dentro da cultura do silêncio, ao perceber que alguma criança insiste em não se submeter às suas ordens busca uma aliada valorosa²: a mãe. Dona Maria ou, simplesmente, mãe:

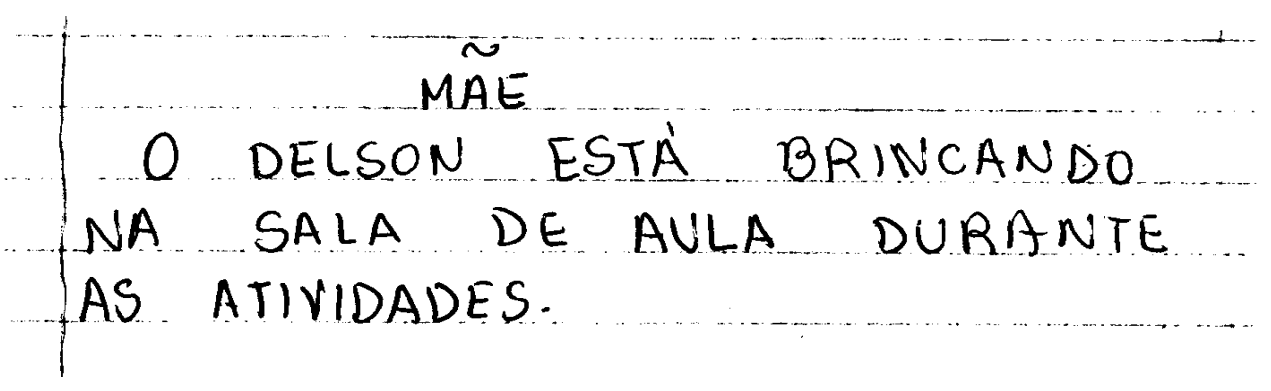

$$
\begin{aligned}
& \text { 2/07 MÄE }
\end{aligned}
$$

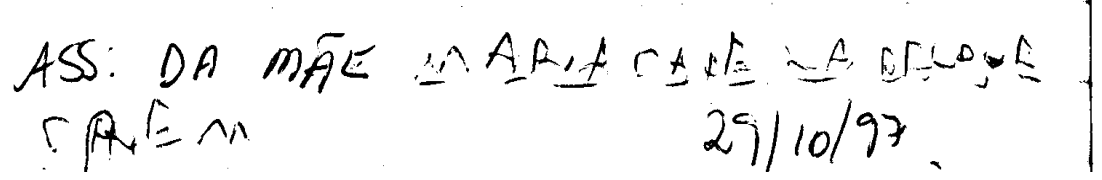

2 Bilhetes como esses que se encontram espalhados pelos cadernos, são vizinhos diletos das "lições" que já apresentadas. 
- Propessora ele tenton esconder SNo bilhetiuho mas en nai $\checkmark f$ descuido dele e fo the dei $\theta$ castigo.

Obrigada

Dona Maria, su filho anda com gracinha na sala de aula, está sempre alhando para trás e de pé. Assim ele fica atrasado com as atividades e copia a tarefa incompleta. Obrigada

wornon and

$$
04 / 1 / 98
$$

- Aar, o Diebon istá descriza. ruigad. distraído, deixando ativodalis incimpletas. falta apuch 2 meritivese

Estudos em Avaliação Educacional, n² 23, jan-jun/2001

131 


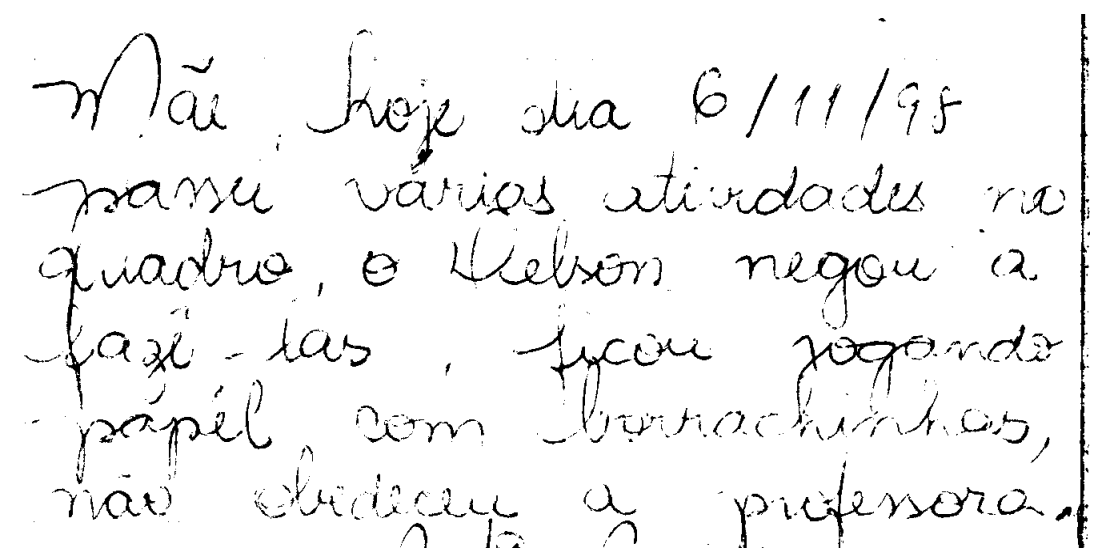

A leitura desses bilhetes evoca a extraordinária figura de Paulo Freire (1994: 25) dizendo:

Baseando-me num excelente estudo de Piaget sobre o código moral da criança, sua representação mental do castigo, a proporção entre a provável causa do castigo e este, falei longamente citando o próprio Piaget, sobre o assunto, defendendo uma relação dialógica, amorosa, entre pais, mães, filhas e filhos, que fosse substituindo o uso dos castigos violentos.

Continuando nosso passeio encontramos Piaget falando da inteligência infantil e que "(...) nada ensina tanto a humanização do juízo e a modéstia verdadeira como o contato cotidiano com os iguais, que exercita o falar franco e que faz adquirir o espírito de camaradagem."

Ao longo da mesma caminhada, vemos Rubem Alves (1983), com muita sensibilidade e sabedoria denunciando:

Todos sabem que o objetivo da educação é executar a terrível transformação: fazer com que as crianças se esqueçam do desejo de prazer que mora nos seus corpos selvagens, para transformálos em patos domesticados, que bamboleiam ao ritmo da utilidade social.

A inquietação de Buscaglia (1997:27) é com o silêncio entre as crianças e os adultos, por isso recomenda: "Talvez a essência da educação 
não seja entupi-los de fatos, e sim ajudá-los a descobrir sua singularidade, ensinar-Ihes a desenvolvê-la e depois Ihe mostrar como doá-la."

Nesse campo de belos pensamentos encontramos Janusz Korczak (1996: 38) alertando:

A criança "acomodada" é o sonho da educação contemporânea: passo a passo, com método, ela procura adormecer, sufocar, destruir tudo que seja a vontade da criança, sua liberdade, a força moral de suas exigências e de suas aspirações. Bom, obediente, gentil, fácil... Por acaso pensamos alguma vez neste homem fraco, covarde, sem energia que a criança corre o risco de se tornar?

Quando viajamos pelas reflexões de Jean Piaget, Paulo Freire, Rubem Alves, Léo Buscaglia, Janusz Korczak... e, inadvertidamente, "trombamos" com bilhetinhos delatando crianças e com burocratas verbosos falando de educação entendemos o significado de vivenciar o confronto violento de dois mundos opostos e lembramo-nos destes versos de Castro Alves:

Oh! Que doce harmonia traz-me a brisa!

Que música suave ao longe soa!

Meu Deus! Como é sublime um canto ardente

Pelas vagas sem fim boiando à toa!

$$
\text { (...) }
$$

Mas que vejo eu aí... Que quadro d'amarguras!

É canto funeral! ... Que tétricas figuras! ...

Que cena infame e vil ... Meu Deus! meu Deus!

[Que horror!]

\section{Algumas conclusões}

Vivemos em um mundo que tem os mais variados e significativos objetos de conhecimento. Contudo, com a bênção da burocracia, fechamse as portas do processo de escolarização para a criança que não aceita decorar a tabuada, àquela que evidencia seu tédio por ter que fazer centenas dos chamados exercícios de "fixação". 
O que podemos falar da criança não que se encanta ao fazer pela nésima vez a lição "escreva as tabuadas do 2 ao nove"? O que podemos falar da criança que não se emociona ao ver uma lição como esta: "escreva números de 0 a 1000"? O que podemos falar da criança que não se extasia diante da lição "Escreva dez vezes cada letra do alfabeto"? O que podemos falar da criança que em um gesto de irreverência fica em pé enquanto os colegas escrevem 500, 510, 520, 530... 1500?

Cremos que o mais razoável para dizermos é que essa criança continua viva, ainda acredita que é possível ser criança, busca conhecer o mundo que a cerca e, acima de tudo, rejeita ser tratada como imbecil. Em outras palavras, é uma criança que ensina, aos que tem alguma sensibilidade, que devemos respeitar aos mais novos.

O que podemos falar de uma escola que impõe autênticos castigos às crianças e que se indigna quando uma delas exibe seu desconforto? $O$ que podemos falar do papel de uma professora que não se interroga "por que meu aluno está desinteressado?" O que podemos falar da vigorosa burocracia escolar que se deleita pronunciando palavras "ocas" aos professores?

Cremos ser legítimo dizer que essa é a escola comprometida com a formação do homem "objeto", do homem dependente. Estas belas e contundentes palavras da poetisa guatemalteca Margarita Carrera (1997: 98) soam de maneira muito sábia "depender é deixar de ser si próprio, é anular-se e viver na sombra, transitar por um caminho que não nos pertence".

É uma escola que tem horror pelo ato de pensar. Que é surda, por exemplo, a estas idéias de Emília Ferreiro (1991: 51): "O que sabemos é que os professores que se atrevem a dar a palavra às crianças e a escutá-las descobrem rapidamente que seu próprio trabalho se torna mais interessante (e inclusive mais divertido), embora seja mais difícil porque os obriga continuamente a pensar".

A escola, entregue a pessoas que não se empolgam com 0 conhecimento, transforma-se em obstáculo para que professores e alunos possam descrever caminhos diversos na aventura intelectual. Isto porque a escola repousa placidamente sobre seu êxito maior: formar pessoas obedientes para se adaptarem a uma sociedade marcada pelas relações de autoritarismo/submissão.

Felizmente existem professores que se indignam quando os burocratas lhes impõem sessões de verbosidade. A indignação diante de 
um palavreado que fala de "humanismo moderno sustentado pelo comportamentalismo", "de um ser que é tábula rasa e que tem as estruturas pré-formadas"... é uma bela manifestação da vontade de viver de forma inteligente. São professores que se emocionam ao ler Rubem Alves, ao assistirem um belo filme como "A sociedade dos poetas mortos", ao sentirem a felicidade barulhenta de seus alunos...

Felizmente existem crianças que brincam com as palavras, com os gestos, com a arrogância, com os medos, com a ignorância, com a insensibilidade, com a pobreza das leituras do professor: são as que insistem em exercitar a criatividade inventando formas para transformar a aula em um espaço inteligente.

A presença de vida inteligente na escola - mantida com dinheiro público - abre janelinhas pelas quais podemos enxergar lá, bem longe, a escola estatal transformando-se em escola pública.

\section{Referências bibliográficas}

ALVES, Rubem. "A escola: fragmento do futuro", palestra proferida durante o "Fórum de Educação do Estado de São Paulo", mimeo., 1983.

BUSCAGLIA, Léo. Vivendo, amando e aprendendo. Rio de Janeiro: Record: Nova Era, 1997.

CARRERA, Margarita. "Latinoamérica: extravasar-se de realidades". In: ESPAÑA, Olmedo. Pensamento filosófico atual na América Central. Londrina: Eduel, 1997.

FERREIRO, Emília. Com todas as letras. São Paulo: Cortez, 1991.

FORRESTER, Viviane. O horror econômico. São Paulo: Editora da Unesp, 1997.

FREIRE, Paulo. A pedagogia do oprimido. Rio de Janeiro: Paz e Terra, 1981.

FREIRE, Paulo. A educação como prática da liberdade. Rio de Janeiro: Paz e Terra, 1992.

GOFFMAN, Erving. Manicômios, prisões e conventos. São Paulo: Perspectiva, 1992. 
GUATTARI, Felix. Revoluções moleculares. São Paulo: Brasiliense, 1986.

JACQUARD, Albert. Filosofia para não-filósofos. Rio de Janeiro: Campus, 1998.

KORCZAK, Janusz. Como amar uma criança. Rio de Janeiro: Paz e terra, 1997.

MORIN, Edgar. Introdução ao pensamento complexo. Lisboa: Publicações Instituto Piaget, 1991.

PIAGET, Jean \& HELLER, J. La autonomia en la escuela. Buenos Aires: Lousada, 1950.

PIAGET, Jean. Sobre a pedagogia. São Paulo: Casa do Psicólogo, 1998.

REIMER, Everett. A escola está morta. Rio de Janeiro: Francisco Alves, 1983. 